Original Article

\title{
Relationship between physical activity and job stress among public office workers
}

\author{
Young-SoOK Yook, $\mathrm{PhD}^{1)}$ \\ 1) Department of Exercise Rehabilitation Welfare, Sungshin Women's University: 2 Bomun-ro, 34 da-gil, \\ Seongbuk-gu, Seoul, Republic of Korea
}

\begin{abstract}
Purpose] This study investigated the relationship between physical activity and job stress among public office workers. [Participants and Methods] We examined the levels of physical activity and job stress of 488 male public officers in Seoul-city, Republic of Korea through self-reported questionnaires. The International Physical Activity Questionnaires and the Korean Occupational Stress Scale were used to evaluate physical activity and job stress, respectively. The level of physical activity was divided into three quantiles (low, moderate, high). [Results] We found no significant difference in job stress by physical activity level. Although a positive correlation between physical activity and job stress was found in the organizational system category, no significant difference was found in the categories of the physical environment, job demand, insufficient job control, interpersonal conflict, job insecurity, lack of reward, and occupational climate. [Conclusion] There was no apparent correlation between physical activity and job stress among public office workers.

Key words: Public office workers, Physical activity, Job stress
\end{abstract}

(This article was submitted Apr. 10, 2020, and was accepted Sep. 22, 2020)

\section{INTRODUCTION}

Physical inactivity is a leading cause of non-communicable diseases and a risk factor of death worldwide following hypertension and smoking ${ }^{1)}$. Physical activity, which is directly linked to health, has been effective in preventing and treating cancer, cardio-cerebrovascular disease, and metabolic syndrome ${ }^{2-4)}$. Furthermore, physical activity is also helpful for mental or psychological health ${ }^{5,6}$. Good mental health can help people to work independently while coping with daily stresses ${ }^{7)}$. Mental health problems, on the other hand, negatively impact the quality of life, work, and social functioning ${ }^{8)}$.

Depression and stress are major factors that cause mental health problems. Recently, interest in occupational stress syndrome has been increasing. Company employees, particularly, suffer from various work-related stresses as members of the organization ${ }^{9)}$. According to a report by the U.S. National Institute for Occupational Safety and Health ${ }^{10)}$, about $60 \%$ of the workers in the U.S. are exposed to extreme job stress due to work. Since job stress is a harmful physical and emotional response that occurs when the job requirements do not match the worker's capabilities, resources, and needs, it can affect various disease states both directly and indirectly ${ }^{11)}$.

Meanwhile, office workers experienced high job stress ${ }^{12}$. Public office workers play a key role in administrative services for the government and the people, and work-related stress during task performance can be counterproductive and cause health problems ${ }^{13)}$. If job stress becomes relatively high, then efficient utilization of human resources in the organization will become impossible, and thus appropriate measures must be taken to deal with it effectively.

Several recent studies have shown that physical activity or exercise positively impacts job stress. Participation in sports activities led to low job stress and high job satisfaction, while the absence of regular exercise was accompanied by high job stress $^{14,15)}$. While physical activity and exercise are considered critical for managing job stress, physical activity and mental 
health have a dose-response relationship ${ }^{16,17)}$. It is, thus, necessary to explore the relationship between levels of physical activity and job stress in terms of dose-response rather than in association with the presence or absence of physical activity as done in previous studies. However, it is difficult to find a study on the relationship between the amount of physical activity and job stress of office workers focusing on the sit-down life.

Therefore, this study investigated the relationship between the level of physical activity and job stress among male office workers using the International Physical Activity Questionnaires (IPAQ) and the Korean Occupational Stress Scale (KOSS), and provides basic data to enhance physical activity and mental health among public office workers.

\section{PARTICIPANTS AND METHODS}

We selected and analyzed data of 448 male public officers working in Seoul-city from 2015 to 2017 who visited the National Fitness Center in South Korea, and completed the questionnaire on daily habits, including smoking, drinking, physical activity, and job stress. This study was conducted in compliance with the ethical principles of the Declaration of Helsinki.

Height and weight were measured using an automatic body measurement device (SH-9600A, Korea). Using this data, we then calculated the body mass index (BMI) using the equation [(Weight $\left.(\mathrm{kg}) / \mathrm{Height}(\mathrm{m})^{2}\right]$. We collected about $10 \mathrm{~mL}$ of blood from a brachial vein 12 hours after meal consumption and used a biochemical analyzer (Selecta XL, Vital scientific, Newton, MA, USA). The analysis included total cholesterol, high-density lipoprotein cholesterol, low-density lipoprotein cholesterol, triglycerides, and fasting blood glucose.

The IPAQ was used to examine the participant's physical activity levels ${ }^{18)}$. We calculated the level of physical activity based on the IPAQ scoring protocol. The physical activity levels, as determined by the IPAQ, were divided into three levels -low, moderate, and high.

1) Low-intensity physical activity: Insufficient activity to fall under 2) and 3) or no activity at all.

2) Moderate-intensity physical activity: At least 20 minutes of intense activity per day for 3 days, at least 5 days of moderate-intensity activity or walking or a total of 5 days of walking, moderate-intensity activity or high-intensity exercise of more than $600 \mathrm{MET}-\mathrm{min} /$ week.

3) High-intensity physical activity: At least 3 days of high-intensity activity 1,500 MET-min/week or at least 7 days of walking, moderate-intensity activity or high-intensity activity of at least 3,000 MET-min/week combined.

The KOSS was used to evaluate levels of job stress ${ }^{19}$. The KOSS comprises 43 items regarding 8 categories: physical environment, job demand, insufficient job control, interpersonal conflict, job insecurity, organizational system, lack of reward, and occupational climate. For each question, participants were asked to answer either 'Not at all', 'No', 'Yes', or 'Strongly Agree'. The items for which a higher score meant higher job stress were scored 1, 2, 3, and 4, while those for which a higher score meant lower job stress were scored 4, 3, 2, and 1. For all subcategories, we used the equation mentioned below to convert the scores. The Cronbach's $\alpha$ for the KOSS was 0.862 across a total of 43 items. The Cronbach's $\alpha$ for this study was 0.833 .

Converted score for each category $=($ actual score - number of items $) \times 100 /($ highest expected score - number of items $)$

Total score of occupational stress $=($ sum of converted scores for the 8 categories $) / 8$

To explore the participants' general characteristics, we calculated the mean (M) and standard deviation (SD) for the continuous variables, and frequency and percentage values for the categorical variables, like drinking and smoking history. The level of physical activity was divided into three quantiles (low, moderate, high). We performed one-way analysis of variance to explore the differences in job stress by physical activity level. We conducted a Person's correlation analysis to identify the relationship between physical activity and job stress. All statistical analysis was conducted using SPSS (version 21.0), and the significance level $(\alpha)$ was set at $\mathrm{p}<0.05$.

\section{RESULTS}

Table 1 presents the participants' physical characteristics. BMI, systolic blood pressure, diastolic blood pressure, total cholesterol, triglyceride, HDL-cholesterol, and fasting blood glucose was no significant differences among the groups. Drinking and smoking history also showed no significant between-group differences. LDL-cholesterol was showing a significant between-group difference $(\mathrm{p}<0.05)$.

Table 2 presents the levels of job stress based on levels of physical activity. Physical environment, job demand, insufficient job, interpersonal conflict, job insecurity, organizational system, lack of reward, occupational climate was showing no significant between-group differences. The total score of job stress also showed no significant between-group differences.

The relationship between physical activity and job stress is shown in Table 3 . The organizational system, a subcategory of job stress, showed a significant positive correlation $(\mathrm{p}<0.05)$. On the other hand, the physical environment, insufficient job control, job insecurity, and occupational climate showed a positive correlation that was not statistically significant. Job demand, interpersonal conflict, and lack of reward showed a negative correlation, but there was no significant difference. 
Table 1. Participants' physical characteristics

\begin{tabular}{|c|c|c|c|}
\hline \multirow{2}{*}{$\begin{array}{l}\text { Physical activity } \\
\text { (MET-min/week) }\end{array}$} & Low $(n=149)$ & Moderate $(n=150)$ & High $(n=149)$ \\
\hline & $1,089.17 \pm 490.14$ & $3,230.90+762.6$ & $8,044.54 \pm 2,480.47$ \\
\hline Age (years) & $47.04 \pm 7.82$ & $47.09 \pm 8.00$ & $48.12 \pm 6.65$ \\
\hline Height $(\mathrm{cm})$ & $167.24 \pm 7.75$ & $168.19 \pm 6.60$ & $168.55 \pm 7.07$ \\
\hline Weight (kg) & $66.98 \pm 10.66$ & $68.28 \pm 9.67$ & $68.29 \pm 8.84$ \\
\hline Body mass Index $\left(\mathrm{kg} / \mathrm{m}^{2}\right)$ & $23.82 \pm 2.38$ & $24.09 \pm 2.70$ & $24.01 \pm 2.49$ \\
\hline Systolic blood pressure (mmHg) & $130.03 \pm 17.46$ & $129.97 \pm 16.22$ & $131.67 \pm 15.21$ \\
\hline Diastolic blood pressure $(\mathrm{mmHg})$ & $80.42 \pm 12.47$ & $80.46 \pm 11.22$ & $81.08 \pm 10.30$ \\
\hline Total Cholesterol (mg/dL) & $199.70 \pm 33.88$ & $194.15 \pm 31.24$ & $191.53 \pm 29.80$ \\
\hline Triglycerides (mg/dL) & $134.64 \pm 99.99$ & $121.74 \pm 64.58$ & $117.49 \pm 79.73$ \\
\hline LDL-Cholesterol (mg/dL) & $123.30 \pm 33.46$ & $114.67 \pm 29.01$ & $114.95 \pm 27.14^{*}$ \\
\hline HDL-Cholesterol (mg/dL) & $53.10 \pm 13.85$ & $55.17 \pm 13.60$ & $54.54 \pm 13.18$ \\
\hline Fasting blood glucose (mg/dL) & $93.21 \pm 16.59$ & $93.67 \pm 22.90$ & $92.14 \pm 13.15$ \\
\hline Drinking $(n)$ & $102(68.9)$ & $108(72.0)$ & $102(68.5)$ \\
\hline Smoking (n) & $71(48.3)$ & $86(57.3)$ & $87(58.4)$ \\
\hline
\end{tabular}

Valves are Mean \pm SD. *Significant difference: $p<0.05$.

Table 2. Job stress by physical activity level

\begin{tabular}{llcc}
\hline Physical activity & Low $(\mathrm{n}=149)$ & Moderate $(\mathrm{n}=150)$ & High $(\mathrm{n}=149)$ \\
\hline Physical environment (scores) & $30.78 \pm 15.99$ & $34.87 \pm 17.9$ & $32.12 \pm 14.63$ \\
Job demand (scores) & $48.46 \pm 15.25$ & $48.97 \pm 16.22$ & $48.69 \pm 11.19$ \\
Insufficient job control (scores) & $47.03 \pm 9.92$ & $47.38 \pm 10.79$ & $47.74 \pm 10.02$ \\
Interpersonal conflict (scores) & $35.94 \pm 9.1$ & $36.09 \pm 9.1$ & $36.45 \pm 10.77$ \\
Job insecurity (scores) & $41.83 \pm 10.55$ & $42.92 \pm 11.78$ & $43.80 \pm 9.29$ \\
Organizational system (scores) & $43.43 \pm 11.44$ & $45.62 \pm 11.75$ & $46.75 \pm 12.48$ \\
Lack of reward (scores) & $43.02 \pm 10.7$ & $45.29 \pm 10.82$ & $45.03 \pm 10.43$ \\
Occupational climate (scores) & $37.52 \pm 13.09$ & $40.66 \pm 14.23$ & $39.87 \pm 11.69$ \\
Total (scores) & $41.01 \pm 6.56$ & $42.73 \pm 6.95$ & $42.57 \pm 6.67$ \\
\hline
\end{tabular}

Valves are Mean $\pm \mathrm{SD}$.

Table 3. Relationship between physical activity and job stress

\begin{tabular}{|c|c|c|c|c|c|c|c|c|c|}
\hline & & $\mathrm{PE}$ & JD & IJC & IC & $\mathrm{JC}$ & OS & LR & $\mathrm{OC}$ \\
\hline Physical activity & r-value & 0.014 & 0.060 & 0.039 & -0.006 & 0.019 & $0.111^{*}$ & -0.022 & 0.038 \\
\hline
\end{tabular}

PE: physical environment; JD: job demand; IJC: insufficient job control; IC: interpersonal conflict; JI: job insecurity; OS: Organizational system; LR: Lack of reward; OC: occupational climate.

*Significant difference: $\mathrm{p}<0.05$.

\section{DISCUSSION}

This study identified the relationship between levels of physical activity and job stress using the IPAQ among 488 male public officers working in the Seoul area. The results of this study showed no significant difference in the job stress of public officers based on physical activity level. A significant positive correlation between physical activity and job stress was found only in one subcategory of job stress, i.e., organizational system.

Job stress is a harmful physical and emotional response arising from the inconsistency between the work requirements and the worker's capabilities, resources, and desire ${ }^{20}$. Excessive job stress negatively impacts various aspects, including chronic illness and the psychological burden of the workers ${ }^{21,22}$. The KOSS by Chang et al. ${ }^{19)}$ used in the present study evaluates a score of 45 or below out of 100 as a very low level, while a score of 56.6 or above is evaluated as very high. In this study, the total score of job stress in public office workers was $41.01 \pm 6.56,42.73 \pm 6.95$, and $42.57 \pm 6.67$ in the low-activity, moderate-activity, and high-activity groups, respectively, which was in the bottom $25 \%$. The results of this study suggest that 
the level of job stress in public office workers was not significantly high.

The effective intervention of personal resources is required to prevent negative outcomes of job stress. Physical activity is effective in not only enhancing physical health, but also preventing cancer, cardio-cerebrovascular disease, and metabolic syndrome. Additionally, it is also essential for stress management in terms of mental health ${ }^{23)}$. The present study revealed no significant difference in job stress by physical activity level across all subcategories of job stress — physical environment, job demand, insufficient job control, interpersonal conflict, job insecurity, organizational system, lack of reward, and occupational climate. According to previous studies, people with higher levels of job stress tended to exercise less ${ }^{24-26)}$. Chon et al. ${ }^{14)}$ also showed that people who exercised regularly had lower levels of job stress as compared to those who did not exercise. This suggests that, contrary to the present findings, physical activity or exercise helps reduce job stress. Future research should include evaluation of physical fitness along with physical activity level based on a subjective questionnaire.

This study also revealed a significant positive correlation between physical activity and job stress regarding the organizational system, which refers to the organization's operation system, intra-organizational conflict, and rational communication. On the other hand, no significant correlation between physical activity and job stress was found for the physical environment, job demand, insufficient job control, interpersonal conflict, job insecurity, lack of reward, and occupational climate. These findings contradicted the findings of previous studies ${ }^{27)}$. In the present study, since a significant correlation was found only between physical activity and organizational system, it can be concluded that there is no apparent link between physical activity and job stress.

Meanwhile, job stress negatively impacts health and heightens the occurrence risk of cardiovascular disease ${ }^{28,29)}$. In this study, LDL-cholesterol, a risk factor of cardiovascular disease, was found to be high in the low-activity group. However, there was no significant difference in BMI, systolic and diastolic blood pressure, total cholesterol, triglycerides, HDL-cholesterol, and fasting blood glucose. Since a significant difference by physical activity was found only in the LDL-cholesterol level, it can be concluded that there is no apparent correlation between job stress and cardiovascular disease. This can be explained by the fact that the study participants were mostly healthy males with low job stress levels.

This study has certain limitations. First, since it is a cross-sectional study, the causal link between physical activity and job stress cannot be clearly defined. Second, the data used in this study comprised self-reported questionnaires, and thus, the subjective evaluation of the participants could not be accurately reflected. Third, the sample was limited to public officers in a single area, and thus, the results cannot be generalized. Moreover, this study was limited to male subjects. Despite these few limitations, we believe that this study has value as it demonstrated the relationship between physical activity and job stress among public office workers.

As such, this study investigated the correlation between the levels of physical activity and job stress among 488 male public officers in the Seoul area. As a result, a significant positive correlation between physical activity and job stress was found only in the organizational system category of job stress. In conclusion, we believe that there is no apparent link between physical activity and job stress among office workers.

\section{Funding}

This work was supported by the Sungshin Women's University Research Grant of 2018.

\section{Conflict of interest}

The author declares no competing interest.

\section{REFERENCES}

1) World Health Organization: Global health risks: mortality and burden of disease attributable to selected major risks. World Health Organization, Geneva, 2009.

2) Burnham TR, Wilcox A: Effects of exercise on physiological and psychological variables in cancer survivors. Med Sci Sports Exerc, 2002 , 34: 1863-1867. [Medline] [CrossRef]

3) Dimeo F, Rumberger BG, Keul J: Aerobic exercise as therapy for cancer fatigue. Med Sci Sports Exerc, 1998, 30: 475-478. [Medline] [CrossRef]

4) Ekelund U, Brage S, Franks PW, et al.: Physical activity energy expenditure predicts progression toward the metabolic syndrome independently of aerobic fitness in middle-aged healthy Caucasians: the Medical Research Council Ely Study. Diabetes Care, 2005, 28: 1195-1200. [Medline] [CrossRef]

5) Dinas PC, Koutedakis Y, Flouris AD: Effects of exercise and physical activity on depression. Ir J Med Sci, 2011, 180: 319-325. [Medline] [CrossRef]

6) Stults-Kolehmainen MA, Sinha R: The effects of stress on physical activity and exercise. Sports Med, 2014, 44: 81-121. [Medline] [CrossRef]

7) World Health Organization: Mental health action plan 2013-2020. World Health Organization, Geneva, 2013.

8) Korniloff K, Vanhala M, Kautiainen H, et al.: Lifetime leisure-time physical activity and the risk of depressive symptoms at the ages of 65-74 years: the FIND2D survey. Prev Med, 2012, 54: 313-315. [Medline] [CrossRef]

9) Chang SJ, Koh SB, Kang MG, et al.: [Epidemiology of psychosocial distress in Korean employees]. J Prev Med Public Health, 2005, 38: 25-37 (in Korean). [Medline]

10) Worker Health Chartbook: National Institute for Occupational Safety and Health. Retrieved 2004, August 22.

11) Lerman C, Karen G: Stress, coping, and health behavior. Health Behavior Education. San Francisco: Tossey-Bass, 1997, pp 113-138.

12) Cha KT, Kim IH, Koh SB, et al.: The association of occupational stress with self-perceived fatigue in white collar employees. Korean J Occup Environ Med, 2008, 20: 182-192. [CrossRef] 
13) Ko KJ, Kim EH, Baek UH, et al.: The relationship between physical activity levels and metabolic syndrome in male white-collar workers. J Phys Ther Sci, 2016, 28: 3041-3046. [Medline] [CrossRef]

14) Chon SH, Kim JY, Cho JJ, et al.: Job characteristics and occupational stress on health behavior in Korean workers. Korean J Fam Med, 2010 , 31: 444-452. [CrossRef]

15) Kouvonen A, Vahtera J, Oksanen T, et al.: Chronic workplace stress and insufficient physical activity: a cohort study. Occup Environ Med, 2013, 70: 3-8. [Medline] [CrossRef]

16) Dunn AL, Trivedi MH, O’Neal HA: Physical activity dose-response effects on outcomes of depression and anxiety. Med Sci Sports Exerc, 2001, 33: S587S597, discussion 609-610. [Medline] [CrossRef]

17) Kettunen O, Vuorimaa T, Vasankari T: A 12-month exercise intervention decreased stress symptoms and increased mental resources among working adultsresults perceived after a 12-month follow-up. Int J Occup Med Environ Health, 2015, 28: 157-168. [Medline] [CrossRef]

18) Craig CL, Marshall AL, Sjöström M, et al.: International physical activity questionnaire: 12-country reliability and validity. Med Sci Sports Exerc, 2003, 35: 1381-1395. [Medline] [CrossRef]

19) Chang SJ, Chang SJ, Koh SB, et al.: Developing an occupational stress scale for Korean employees. Korean J Occup Enviro Med, 2005, 17: 297-317. [CrossRef]

20) National Institute for Occupational Safety and Health: Stress at work (Publication No. 99-101). Washington DC: Department of Health and Human Services, National Institute for Occupational Safety and Health, 1999.

21) Cho JJ, Kim JY, Byun JS: Occupational stress on risk factors for cardiovascular diseases and metabolic syndrome. Korean J Occup Enviro Med, 2006, 18: 209-220. [CrossRef]

22) Shigemi J, Mino Y, Ohtsu T, et al.: Effects of perceived job stress on mental health. A longitudinal survey in a Japanese electronics company. Eur J Epidemiol, 2000, 16: 371-376. [Medline] [CrossRef]

23) Salmon P: Effects of physical exercise on anxiety, depression, and sensitivity to stress: a unifying theory. Clin Psychol Rev, 2001, 21: 33-61. [Medline] [CrossRef]

24) Hellerstedt WL, Jeffery RW: The association of job strain and health behaviours in men and women. Int J Epidemiol, 1997, 26: 575-583. [Medline] [CrossRef]

25) Kouvonen A, Kivimäki M, Elovainio M, et al.: Job strain and leisure-time physical activity in female and male public sector employees. Prev Med, 2005, 41: 532-539. [Medline] [CrossRef]

26) Yang X, Telama R, Hirvensalo M, et al.: Sustained involvement in youth sports activities predicts reduced chronic job strain in early midlife. J Occup Environ Med, 2010, 52: 1154-1159. [Medline] [CrossRef]

27) Kim YS, Park YS, Allegrante JP, et al.: Relationship between physical activity and general mental health. Prev Med, 2012, 55: 458-463. [Medline] [CrossRef]

28) Hwang CK, Koh SB, Chang SJ, et al.: Occupational stress in relation to cerebrovascular and cardiovascular disease: longitudinal analysis from the NSDSOS project. Korean J Occup Enviro Med, 2007, 19: 105-114. [CrossRef]

29) Koh SB, Chang SJ, Park JK, et al.: Occupational stress and risk factors for cardiovascular diseases. Korean J Occup Enviro Med, 2005, 17: 186-198. [CrossRef] 